\title{
SSynthesis
}

International Scientific Conference of IT and Business-Related Research

\section{SAVREMENI MENADŽMENT ZAOKRETA: RAZVOJ I INVESTIRANJE}

\author{
MODERN TURNAROUND MANAGEMENT: DEVELOPMENT AND INVESTMENTS
}

\author{
Ljiljana Jeremić \\ Univerzitet Singidunum, Poslovni fakultet u Beogradu, Danijelova 32, Beograd, Srbija
}

\begin{abstract}
Apstrakt:
Ekonomsko-finansijska kriza dovela je do mnogih poslovnih problema. Proces upravljanja uslovio je promene u organizaciji poslovanja $\mathrm{i}$ investiranja u kompanijama. Jedan od efikasnih načina rešavanja nastalih poslovnih problema jeste finansijsko restrukturiranje $\mathrm{u}$ određenoj fazi procesa menadžmenta zaokreta. Kompanije nastoje da investiranje izvrše efikasno uz što niže troškove finansiranja. Stabilazacija poslovanja predstavlja osnovu za poslovnu bazu radi daljeg rasta i razvoja. Savremeno poslovanje u uslovima tržišne konkurencije zahteva primenu novih tehnika od strane menadžmenta koje putem efikasnog izbora investiranja omogućavaju zaokret u poslovanju.
\end{abstract}

\section{Ključne reči:}

savremeno upravljanje zaokretom (menadžment zaokreta), investicioni troškovi, ekonomska efikasnost investiranja.

\section{UVOD}

Poslovanje u današnjim uslovima zahteva dobru organizaciju u svim poslovnim domenima kako bi kompanije mogle da se bore bilo za opstanak ili učvršćivanje dominacije na tržištu. U cilju donošenja odluke veoma je važno utvrditi uzrok zastoja ili pada poslovne aktivnosti. Savremeno upravljanje u poslednjoj deceniji sve više koristi strategiju menadžmenta zaokreta. U uslovima svetske ekonomsko-finansijske krize kompanije se susreću sa gubicima i prestankom rada, kao najtežim ishodom pada poslovne aktivnosti. Početak pada ogleda se u postepenom smanjenju poslovnih performansi što vodi ka finansijskim gubicima. Prateći problemi koji se pojavljuju u tim uslovima su: gubitak konkurentne pozicije na tržištu, gubitak klijenata i otpuštanje zaposlenih (Khandwalla, 1998). Gubitak pozicije na tržištu uvek se meri za date kompanije u odnosu na istu granu privrede.

Posledice poslovnih problema odražavaju se na organizacione celine, tako da je potrebno uspostaviti nov organizacioni oblik u okviru promena koje se preduzimaju. Jedan od načina rešavanja nastale poslovne krize jeste uspostavljanje menadžmenta zaokreta. Savremeno upravljanje zaokretom pokazuje svoje pozitivne rezultate, kada kao rezultat novouspostavljenog upravljanja kompanija ostvari značajan rast profita za period od dve do tri godine i uspe da se repozicionira na tržištu u okviru svoje grane. $\mathrm{Na}$ taj način kompanija pokazuje da je prošla

\section{Abstract:}

The economic-financial crisis has triggered numerous business problems. Management process has brought about change in organization and investment process in enterprises. One of the most efficient ways of solving business issues is financial restructuring at a certain stage of turnaround management process. The companies are trying to make investments efficiently with lower costs of financing. Business stabilization is considered a basis for further growth and development. Modern business in competitive market conditions require new management techniques that would enable business turnaround through effective choice of investments.

\section{Key words:}

modern management turnaround (turnaround management), investment costs, economic investment efficiency.

transformaciju i da ulazi u pozitivan ciklus rasta i razvoja. Različiti faktori dovode do neophodnih promena, najčešće su u vezi sa tehnološkim razvojem i visokim troškovima kapitala. Prema stavu teoretičara Slatter-a (2006) koji zaključuje da ako je dobit (pre oporezovanja) povećana u četiri od sledećih šest godina (od krize perioda), onda preokret može da se tretira kao uspešan. Slično ovom mišljenju O’Neil (1986) je imao stav da poslovni preokret može da uspe kada kompanija ima veći neto prihod od prosečnog granskog u periodu od naredne tri godine od započetih promena.

U praksi se pokazalo da savremeno upravljanje putem zaokreta poslovnih problema može da se primeni uspešno u već razvijenim ili "zrelim" kompanijama ili privredi, a isto tako i kod nedovoljno razvijenih kompanija ili privredi. U zavisnosti da li je reč o zreloj kompaniji (privredi) ili ne, posmatraju se i analiziraju različiti faktori uticaja koji su doveli do poremećaja. Poseban problem predstavljaju "teške situacije u zrelim industrijama gde je opala tražnja, postoji visoka lojalnost kupaca a nema jake konkurencije" (http: turnaround management, pdf). U takvim uslovima odabir plana poslovne orijentacije mora da bude u direktnoj vezi sa primenom novih tehnologija. Primena novih tehnologija zahteva jak sopstveni istraživačko-razvojni potencijal ili povoljne finansijske uslove za nabavku i primenu visokorazvijenih tehničko-tehnoloških sredstava. U tom slučaju postavlja se procena finansijske sposobnosti kompanija da se uz što niže troškove kapitala obavi finansiranje. 
Generalno posmatrano, zrele kompanije se bolje snalaze od mlađih, jer su već prešle jedan životni poslovni ciklus i znaju da se u cilju ostvarenja zadovoljavajućeg nivoa profita mora brzo delovati (Pascale, 1999).

\section{ZNAČAJ UPRAVLJANJA ZAOKRETOM}

Upravljanje zaokretom (preokretom) predstavlja sistematsko sprovođenje mera u nekoliko faza. One se preduzimaju u situaciji kada kompanija posluje sa ozbiljnim finansijskim problemima, kada zaostaje u odnosu na svoju granu i preti joj opasnost od propadanja. U okolnostima kada kompanija posluje ekonomski loše donošenjem planskih mera, modelom upravljanja zaokretom, mogu se stvoriti povoljni uslovi poslovanja. Upravlajnje zaokretom predstavlja dobar model za zaustavljanje pada poslovanja, ili ako je već došlo do pada poslovne aktivnosti se vraćaju uz profit. Na taj način, postiže se jedan od ciljeva poslovanja, zadovoljavajući nivo profita kao rezultat preduzetih mera. Prema jednom od scenaria faze upravljanja (Harlan, 2001) se odvijaju u pet etapa. U prvoj fazi odvijaju se aktivnosti odabira menadžmenta koji će voditi proces promena. Sledi faza ocenjivanja procene problema i priprema plana aktivnosti koju prati hitna faza, gde se preduzimaju neophodne mere za otklanjanje problema. U četvrtoj fazi stabilizacije sprovode se planovi, analiziraju ostvareni rezultati i ukoliko je potrebno preduzimaju se dodatne mere.

\begin{tabular}{|c|c|c|}
\hline Faze & Opis & Akcije \\
\hline 1 & $\begin{array}{l}\text { Promena } \\
\text { menadžment } \\
\text { scene }\end{array}$ & $\begin{array}{l}\text { 1. Odbor direktora ili višeg rukovodstva } \\
\text { odlučuje o neophodnoj tranziciji. } \\
\text { 2. Posrednik za preokret se bira kao organ sa } \\
\text { autoritetom. }\end{array}$ \\
\hline 2 & $\begin{array}{l}\text { Faze ocenji- } \\
\quad \text { vanja }\end{array}$ & $\begin{array}{l}\text { 1. Priroda i obim problema sedefiniše. } \\
\text { 2. Tip preokreta, strateški ili operativan. } \\
\text { 3. Akcioni plan je pripremljen. }\end{array}$ \\
\hline 3 & Hitna faza & $\begin{array}{l}\text { 1. Kompanija na ivici neuspeha mora da } \\
\text { uradi sve što je potrebno kako bi preži- } \\
\text { vela. }\end{array}$ \\
\hline 4 & $\begin{array}{c}\text { Faza stabili- } \\
\text { zacije }\end{array}$ & $\begin{array}{l}\text { 1. Rešeni neposredni problemi. } \\
\text { 2. Planovi doneti kako bi se poboljšao rad i } \\
\text { strateške performanse. } \\
\text { 3. Rezultati su procenjeni kao prihvatljivi. } \\
\text { 4. Kada rezultati pokazuju nedovoljnost, } \\
\text { likvidacija, prodaja ili spajanje predstav- } \\
\text { ljanju moguće opcije. }\end{array}$ \\
\hline 5 & $\underset{\substack{\text { Povratak na } \\
\text { normalnu fazu }}}{\mid}$ & 1. Normalne poslovne operacije. \\
\hline
\end{tabular}

Slika 1: Faze preokreta

Izvor: Harlan, D.P. (2001)

U završnoj fazi uspostavljeno je stabilno poslovanje uz tržišnu konkurentnost i normalne poslovne operacije. Kompanija je izvršila promenu poslovanja putem menadžmenta zaokreta.

Osnovni problem u procesu upravljanja je da se na vreme uoči stagnacija i blagovremeno preduzmu mere oporavka. U uslovima tržišne konkurencije i brzih tehničko-tehnoloških promena poslovna borba za osvajanje i zadržavanje postojećih kupaca nameće se kao imperativ poslovanja. U svim ovim akcijama najvažniji faktor predstavljaju kvalitetni zaposleni. Oni kreiraju posao i predstavljaju osnovne nosioce promena i razvoja. U procesu sprovođenja promena često dolazi do kadrovskih promena. Investiranje u kreativne kadrove je jedan od najznačajnijih domena upravljanja zaokretom

\subsection{RAZLOZI ZA NEUSPEH I PAD}

Osnovni razlozi pada u organizaciji poslovanja su faktori unutrašnje i spoljne prirode. Faktori koji utiču na poslovanje kompanije moraju se definisati u skali snage i slabosti u odnosu na spoljne pretnje i okolnosti u okviru SWOT analize. Kada kompanija u potpunosti prihvati rezultate analize i odredi pravac kretanja promena (Schendel et al., 1976), onda govorimo o realizaciji upravljanja zaokretom i izlasku iz problema poslovanja.

Glavni razlozi koji izazivaju poslovni pad su nesklad između unutrašnjih i dejstva spoljnih faktora. U praksi to može da znači da preduzeće ima zastareli proizvod koji ne može da se održi na tržištu, usled jake konkurencije. To je razlog zbog koga kompanija treba da oceni svoje unutrašnje mogućnosti u odnosu na gransko okruženje.

Projekcija plana zaokreta razlikuje se, kao što je prethodno navedeno, kada je reč o ekonomski razvijenoj kompaniji ili privredi, i kompaniji odnosno privredi u razvoju. Tako se studije slučaja nerazvijenih kompanija ili kompanija u razvoju zasnivaju na kombinaciji određenih elementa upravljanja zaokretom. Prema ovim studijama (devet studija slučaja, pet iz javnog i četiri iz privatnog sektora) osnova tih promena zasniva se na sledećim elementima (Khandwalla, 1998):

1. Promena posrednika, sa jakim osećajem za cilj misije, poželjno je da to bude lice van unutrašnje organizacije,

2. Formiranje, izgradnja poverenja putem izuzetnih poslovnih performansi,

3. Mobilizacija običnih službenika tako što će se ukljućiti u akciju ostvarenja ciljeva organizacije,

4. Brzi, isplativi projekti za neposrednu pomoć,

5. Smanjenje ozbiljnih spoljnih pritisaka koji se odnose na delatnost, finansije, ključne resurse, sve zainteresovane partnere i slično,

6. Mobilizacija spoljnih resursa i korišćenje ekoloških povoljnosti,

7. Jačanje mehanizma koji utiču na okruženje (marketing i odnosi sa javnošću),

8. Selektivne promene proizvodnog miksa, koncentrisanjem isplativijih proizvoda,

9. Selektivno jačanje funkcije sistema upravljanja, posebno u okviru finansijske kontrole,

10. Motivisanje menadžera putem učešća, autonomije, izazovnih zadataka, postavljenjem na funkciju, itd.

11. Koordinacija rada održavanjem redovnih sednica i međutimskog suočavanja,

12. Kontrola performansi postavljenih ciljeva utvrđivanjem odgovornosti, često u vezi sa stvaranjem profita i kontrolom troškova.

Osnovni principi (Turnaround Management, 2014) na kojima se zasniva upravljenje zaokretom su:

1. Sposobnost generisanja novčanih tokova u okviru poslovanja osnovne delatnosti.

2. Dovoljni dugoročni ili potpuno novi izvori finansiranja.

3. Dobro organizovan tim menadžmenta sa potpunom kontrolom rada kompanije.

Većina autora smatra da suština promena uspešnog preokreta poslovanja polazi od postojanja dobro organizovane 
osnovne delatnosti. U tom smislu, neophodno je da kompanija ima dobro definisan proizvod, lojalne kupce, dobar odnos sa sigurnim isporukama dobavljača i što je najvažnije dobru struktur zaposlenih. Za sve navedene aktivnosti potrebni su dovoljni finansijski izvori uz što niže troškove finansiranja.

\subsection{FINANSIJSKO RESTRUKTURIRANJE}

Poslovi finansijskog restrukturiranja stavljaju akcenat na finansijsku funkciju, što je značajno za uspostavljanje solventnosti kompanije. Propisi kojima se reguliše solventnost razlikuju se prema zemljama. U sledećem pregledu možemo da vidimo kako se razlikuju propisi o solventnosti u dve ekonomski razvijene zemlje.

Pravni propisi koji se bave regulisanjem određenih poslovnih poremaćaja u Srbiji, kada kompanija duže vremena nije u stanju da izmiruje svoje obaveze, predviđeni su Zakonom o stečaju (Službeni glasnik Republike Srbije, 2014). U članu 4 ovog Zakona, sve poverioce klase stavlja u isti isplatni red ukoliko se vrši namirenje obaveza od strane dužnika. U postupku stečaja, upravnik kao glavni administrator može da uzme kredit, ali samo do visine sredstava kojima raspolaže prema članu 27 istog Zakona. Pregovori o obavezama mogu se obaviti u okviru rada Skupštine poverilaca. Ovaj pravni akt jednim delom se bavi problematikom koja se odnosi na solventnost, odnosno nesolventnost koja je dovela do zaustavljanja rada kompanije. Ukoliko bismo primenjivali sistem upravljanja zaokretom, onda bismo pre samog poslovnog pada morali da preduzimamo planske aktivnosti koje su predstavljene Slikom 1. Blagovremeno preduzimanje planskih aktivnosti osnovni je preduslov uspešnog rešavanja krizne poslovne situacije.

\begin{tabular}{|c|c|c|}
\hline Karakteristike & SAD & Nemačka \\
\hline Kontrola prava & $\begin{array}{l}\text { Dužnik kontroliše: u većini slučajeva prethod- } \\
\text { ni menadžeri zadržavaju poziciju; u nastavku } \\
\text { procesa imenuju se novi rukovodioci. }\end{array}$ & $\begin{array}{l}\text { Stečajni sud imenuje stečajnom dužniku administratora ili } \\
\text { mu dozvoljava da ostane u posedu imovine. Do sada sudovi } \\
\text { nisu bili voljni da daju ovo pravo dužniku. }\end{array}$ \\
\hline Zahtevi solventnosti & Firma ne treba da bude nesolventna. & $\begin{array}{l}\text { Firma mora da bude pod stečajem ili da se suočava sa zna- } \\
\text { čajnim rizikom moguće nelikvidnosti. } \\
\text { Kriterijumi: } \\
\text { 1) ne mogu da odgovore obavezama prema poveriocima, } \\
\text { 2) prezadužena, što je dovelo do značajnog rizika da firma } \\
\text { neće moći da ispuni buduća dugovanja. }\end{array}$ \\
\hline $\begin{array}{l}\text { Automatsko odla- } \\
\text { ganje }\end{array}$ & $\begin{array}{l}\text { Većina potraživanja se odlaže (izuzetak su npr. } \\
\text { lizing obaveze). }\end{array}$ & $\begin{array}{l}\text { Automatski se odlažu neobezbeđena potraživanja, najmanje } \\
\text { za tri meseca. }\end{array}$ \\
\hline $\begin{array}{l}\text { Obnavljanje prego- } \\
\text { vora o obavezama }\end{array}$ & $\begin{array}{l}\text { Veliko diskreciono pravo da se ponovo prego- } \\
\text { vara o dugu. Dozvoljena razmena dug-kapital. }\end{array}$ & $\begin{array}{l}\text { Dozvoljeno obnavljanje pregovora sa svim poveriocima. O } \\
\text { obezbeđenim i neobezbeđenim potraživanjima mogu da } \\
\text { glasaju o tome u svojoj klasi potraživanja. Nije dozvoljena } \\
\text { razmena dug-kapital. }\end{array}$ \\
\hline $\begin{array}{l}\text { Dopunjavanje } \\
\text { odredbi }\end{array}$ & $\begin{array}{l}\text { Da, ako je plan ravnopravan prema svim kla- } \\
\text { sama obaveza. }\end{array}$ & $\begin{array}{l}\text { Da, ako sud može da utvrdi da je plan najbolji u interesu } \\
\text { poslovne grupe. }\end{array}$ \\
\hline $\begin{array}{l}\text { Ograničenja firmi } \\
\text { prema načelu stalno- } \\
\text { sti poslovanja }\end{array}$ & Malo. & Svi poverioci glasaju o planu. \\
\hline $\begin{array}{l}\text { Novo finansiranje } \\
\text { reorganizacije }\end{array}$ & $\begin{array}{l}\text { Novo finansiranje se lako sprovodi, jer ima pri- } \\
\text { oritet nad postojećim zahtevima i postoje insti- } \\
\text { tucije koje su specijalizovane za to. }\end{array}$ & $\begin{array}{l}\text { Novo finansiranje može da se organizuje. Mora se otplatiti u } \\
\text { celini, pre nego što se namire poverioci ("poverioci vlasni- } \\
\text { ci”). Nema specijalizovanih finansijskih institucija. Nemač- } \\
\text { ke banke ga vide kao nužno zlo. }\end{array}$ \\
\hline $\begin{array}{l}\text { Očuvanje rezidual- } \\
\text { nih prava akciona- } \\
\text { rima }\end{array}$ & $\begin{array}{l}\text { U većini slučajeva odstupanja od apsolutnog } \\
\text { prioriteta u korist kapital akcija. }\end{array}$ & $\begin{array}{l}\text { Odstupanja se mogu dogovoriti, ali se moraju obaviti dogo- } \\
\text { vornim glasanjem. }\end{array}$ \\
\hline
\end{tabular}

Slika 2. Poređenje propisa o nesolventnosti Nemačke i SAD

Izvor: Franks, J.R. et al. (1976); Aichholzer et al. (2003) str. 7
Primena upravljanja metodom zaokreta prisutna je skoro tri decenije u svetskoj praksi, a ponovo se aktivnije primenjuje u periodu najnovije ekonomsko-finansijske krize od 2008. godine. U okviru projekcije promena poslovanja nakon stabilizacije krize i uspostavljanja novog tima lidera najznačajnije su organizacione promene i finansijsko restrukturiranje. Finansijsko restukturiranje je ključna završna aktivnost čiji je osnovni zadatak da formira zdravu finansijsku bazu.

Pitanje visine troškova, pri sprovođenju strategije upravljanja preokretom, zahteva stabilne izvore finansiranja koji podržavaju oporavak i dalji razvoj. Finansijsko restrukturiranje ne može da se sprovodi bez pomoći banaka i finansijskih institucija. U većini slučajeva odluke o korišćenju finansijskih sredstava se donose detaljnom analizom izbora sredstava sa najnižim troškovima. Smanjenje ukupnih troškova, troškova finansiranja i kamata postaje izuzetno važno.

\section{LITERATURA}

Aichholzer, C, Hardymon, F., Lerner, J., \& Petzel, J. (2003). The Challenges of German Turnaround Investing. Cambridge: Harvard Business School.

Franks, J.R., Nyborg, K.G., \& Torous, W.N. (1996). A comparison of US, UK, and German insolvency codes. Financial management, 25(3), 86-101.

Hambrick, D.C., Schecter, S.M. (1983). Turnaround Strategies for Mature Industrial Product Business Units. Academy of Management Journal, 26(2), 231-248.

Stečajni sud imenuje stečajnom dužniku administratora ili o sada sudovi Firma mora da bude pod stečajem ili da se suočava sa zna-

1) ne mogu da odgovore obavezama prema poveriocima

prezadužena, sto je dovelo do značajnog rizika da firma Automatski se odlažu neobezbeđena potraživanja, najmanje meseca.

obezbeđenim i neobezbeđenim potraživanjima mogu da

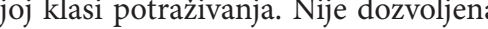
Da, ako sud može da utvrdi da je plan najbolji u interesu Svi poverioci glasaju o planu.

Novo finansiranje može da se organizuje. Mora se otplatiti u celini, pre nego što se namire poverioci ("poverioci vlasni. Nema specijalizovanih finansijskih institucija. Nemač-

Odstupanja se mogu dogovoriti, ali se moraju obaviti dogoornim glasanjem. 
Harlan, D.P. (2001). Principles of Corporate Renewal. Ann Arbor, MI: Michigan University Press.

Khandwalla, P.N. (1998). Effective Turnaround of Sick Enterprises (Indian Experience): Text and Cases, London: Commonwealth Secretariat.

Miller, D., Friesen, P. (1984). A Longitudinal Study Of The Corporate Life Cycle. Management Science, 30, 1161-1183.

O’Neill, H. (1986). An Analysis Of The Turnaround Strategy In Commercial Banking. Journal of Management Studies, 23, $165-188$

Pascale, R.T. (1999). Surfing the edge of the chaos. Sloan Management Review, 40(3),83-94.
Schendel, D., Patton, J.R., \& Riggs, J. (1976). Corporate Turnaround Strategies: A Study Of Profit Decline And Recovery. Journal of General Management, 3(3), 3.

Slatter, S., Lovett, D., \& Barlow, L. (2006). Leading Corporate Turnaround: How Leaders Fix Troubled Companies. San Francisco: Jossey Boss.

Službeni glasnik Republike Srbije. (2014). Zakon o stečaju, br. 104/1999, 99/2011, 71/2012, 83/2014. Preuzeto sa http:// www.paragraf.rs/propisi_download/zakon_o_stecaju.pdf

Turnaround Management. (2014). A Process and Strategy Focus. Preuzeto sa http://shodhganga.inflibnet.ac.in:8080/jspui/ bitstream/10603/8694/14/14_chapter\%205.pdf 